\title{
Salt Tolerant Wheat Landraces and Gly II Transformed Lines Show Distinct Biochemical Mechanisms of Stress Tolerance
}

\author{
L. KAUR ${ }^{1}$, B. AsthiR* and N.S. BAINs ${ }^{2}$ \\ ${ }^{1}$ Department of Biochemistry, Punjab Agricultural University, Ludhiana-141004, Punjab, India \\ ${ }^{2}$ Department of Plant Breeding and Genetics, Punjab Agricultural University, \\ Ludhiana-141004, Punjab, India \\ (Received 3 August 2018; Accepted 8 February 2019; \\ Communicated by S. Gottwald)
}

The present investigation was carried out to study the distinct salt tolerance mechanism in two sets of material, Gly II transgenics and Kharchia landraces. The Gly II transgenics were developed for glyoxalase II (osglyII) gene (GenBank accession no. AY054407) from Oryza sativa through Agrobacterium mediated method in the background of wheat cultivar PBW 621. Kharchia 65 is a salt tolerant landrace derivative developed from Kharchia local which is native to saline soils of Rajasthan. The six wheat genotypes, viz. Kharchia local, Kharchia 65, PBW 621, G-2-2, G-3-4 and G-1-13 were evaluated for growth parameters, antioxidant enzymes and contents of glutathione, ascorbic acid, malondialdehyde (MDA), $\mathrm{H}_{2} \mathrm{O}_{2}$, sugars, chlorophyll, carotenoid, electrolyte leakage (EL) and $\mathrm{Na}^{+}, \mathrm{K}^{+}$under control and two salt treatments $(150 \mathrm{mM}$ and $250 \mathrm{mM} \mathrm{NaCl})$. The activities of antioxidant enzymes, glutathione, sugar content increased in both GlyII and Kharchia genotypes as compared to PBW 621. The GlyII activity increased (77-84\%) in GlyII genotypes alongwith content of reduced glutathione (GSH) to maintain redox homeostasis. Apparently, GlyII and Kharchia genotypes exhibited minimum oxidative stress due to low content of $\mathrm{MDA}, \mathrm{H}_{2} \mathrm{O}_{2}$, diminished EL and thereby causing less growth reduction and maintaining high chlorophyll and carotenoid level as compared to PBW 621. In addition, Gly II transgenic material and Kharchia lines showed less $\mathrm{Na}^{+}$accumulation, greater seedling biomass and sugar content due to its salt tolerance mechanism. We infer that GlyII activity enhances GSH which play significant role in detoxifying ROS to establish stress homeostasis. The route for generation of GSH is via ascorbate-glutathione pathway mediated by glutathione reductase. Hence, GlyII transgenics and Kharchia genotypes can diminish salt stress following above mechanism.

Keywords: antioxidants, GlyII transgenics, glyoxalase pathway, wheat, salt treatments

\footnotetext{
Abbreviations: GlyII, glyoxalase II; GPX, glutathione peroxidase; GST, glutathione s transferase; SOD, superoxide dismutase; GR, glutathione reductase; ROS, reactive oxygen species; GSH, reduced glutathione; EL, electrolyte leakage; MDA, malondialdehyde; MG, methylglyoxal
}

\footnotetext{
*Corresponding author; E-mail: b.asthir@rediffmail.com
} 


\section{Introduction}

Wheat (Triticum aestivum L.) is a major cereal crop and staple food for about one third of world's population (Hussain et al. 2002). Wheat is cultivated in tropical and sub-tropical regions under both rain-fed and irrigated conditions. Owing to its wide cultivation, wheat production is prone to adverse effect of various abiotic stresses (Rahaie et al. 2013), and $60 \%$ loss of crop production is caused by salt stress (Xie et al. 2016). Wheat is a moderately salt tolerant crop (Munns et al. 2011) but its growth reduces when soil salinity rises to $100 \mathrm{mM} \mathrm{NaCl}$. However, very few wheat genotypes having salt tolerance mechanism have been identified so far (Sairam et al. 2002).

Salinity has detrimental effects on growth and development processes of plants. Under salt stress, hyperosmotic and hyperionic (ion toxicity) stresses occur due to low water potential of soil and excess sodium ion accumulation within the plant (Ashraf 2004). Of 230 million ha of irrigated land, 45 million ha (19.5\%) have already been damaged by salt (FAO 2016). When plants are exposed to salinity, reactive oxygen species (ROS) such as hydrogen peroxide, superoxide radical and hydroxyl radical are produced by a number of metabolic pathways (Hoque et al. 2012). These free radicals disturb normal metabolism by peroxidising membrane lipids and denaturing proteins, photosynthetic pigments and nucleic acids (Das and Roychoudhury 2014; Kapoor 2015). However, plants have different defence mechanism to cope with the potential damage of salinity like accumulation of osmolytes (osmotic adjustments), compartmentalization of $\mathrm{Na}^{+}$and antioxidant system. The enzymatic antioxidants are superoxide dismutase, glutathione peroxidase, glutathione reductase, glutathione S-transferase, ascorbate peroxidase and non-enzymatic are ascorbate, glutathione and carotenoid (Miller et al. 2010).

Passaia et al. (2013) reported higher expression analysis of CATA and POX1 in conjunction with increased levels of oxidative stress metabolites in salt susceptible rice M148 plants as compared to tolerant CSR10 plants. They inferred that M148 plants experienced higher oxidative stress due to increased build up of ROS species that needed more amount of catalase activity to establish homeostasis under stress conditions. Singh et al. (2018) also correlated ionic modulations with salt responsive genes in rice.

In addition to the generation of ROS, accumulation of a toxic compound, methylglyoxal (MG) has been reported under salt stress condition (Ghosh et al. 2014) and detoxification of this compound via glyoxalase I (GlyI) and glyoxalase II (GlyII) enzymes might be a strategy for tolerance against various abiotic stresses (Hoque et al. 2016; Gupta et al. 2018). Methylglyoxal is a cytotoxic metabolite which initiates stress induced signalling cascade via increasing the production of ROS, that results in modification or damage to membrane lipids or proteins which are involved in various transduction pathways that eventually culminates in cell death (Hoque et al. 2016). The transgenic plants overexpressing glyoxalase genes for GlyI or GlyII enzymes have better MG and ROS levels than non-transgenic plants when exposed to stress conditions, as these transgenic plants can tolerate high levels of salt stress (Singla-Pareek 2008). In this MG catabolic pathway, GlyI enzyme isomerizes hemithioacetal which synthesized non-enzymatically with MG and reduced form of glutathione (GSH), into S-D-lactoylglutathione, while GlyII enzyme 
catalyzes the hydrolysis of this thioester to D-lactate and regenerates GSH. So, the overexpression of glyoxalases could result in increased level of GSH that probably helps to detoxify ROS which in turn enhances tolerance against salt stress.

The present study is based on a set of three GlyII transgenic wheat lines alongwith recipient line PBW 621. PBW 621 is a cultivar grown in the North Western Plains of India and is a selection from Kachu's lines developed at CIMMYT, Mexico. Besides GlyII transgenics and its reference line, the study also includes the best known salt tolerant landrace of India, Kharchia local (Gorham et al. 1987) alongwith its commercially grown derivative, Kharchia 65 . Kharchia 65 is a highly salt tolerant wheat genotype that has been extensively used in breeding programmes to generate salt tolerant cultivars (Oyiga et al. 2016).

The two distinct types of salt tolerant lines in this study are likely to be based on strong genetic mechanisms capable of rapid or constitutive response to salinity stress. Using a simple biochemical assays, these responses were characterized using an array of physiobiochemical traits. This study delineates the biochemical consequences of two distinct salt tolerance systems, one owing its origin to selection and the spontaneous genetic changes in the salt affected environment of western Rajasthan (Kharchia local and Kharchia 65) and the other based on insertion of constitutively expressed transgene for a single metabolic step.

\section{Material and Methods}

The wheat GlyII transformed lines were developed for glyoxalase II (osglyII) gene (GenBank accession no. AY054407) from Oryza sativa through Agrobacterium mediated method in the background of wheat cultivar PBW 621 (Kaur 2014). The plasmid pCambia1304 served as the DNA construct backbone. The transgenic status of the plants $\left(\mathrm{T}_{0}\right)$ was confirmed through histochemical GUS assay, PCR based analysis and amplicon sequences of GlyII gene as well as promoter, terminator and marker genes of the construct (Kaur 2014). The inheritance of the transgene was monitored in successive generations and three progenies (viz. G-2-2, G-3-4 and G-1-13) which were homozygous for GlyII gene and represented independent transformation events were selected. PBW 621, the wheat cultivar in which transformation was carried was included in the study to serve as reference material for the three transgenic lines. The highly salt tolerant wheat line Kharchia 65 and its landrace Kharchia local were included in the study as test lines in their own right and also to serve as a tolerant benchmark. Kharchia 65 is a derivative of Kharchia local developed through backcrossing with rust resistant wheat. The selected wheat genotypes Kharchia local, Kharchia 65, PBW 621 and Gly II lines (G-2-2, G-3-4 and G-1-13) were obtained from Department of Plant Breeding and Genetics PAU, Ludhiana. After 3 days of germination, the cultivars were transferred to hydroponic system in plastic trays containing 8 L Hoagland's solution (Hoagland and Arnon 1950) under control and salt stressed conditions $(150 \mathrm{mM}$ and $250 \mathrm{mM} \mathrm{NaCl})$. The salt stress was applied by adding $\mathrm{NaCl}, \mathrm{Na}_{2} \mathrm{SO}_{4}$ and $\mathrm{CaCl}_{2}$, keeping $\mathrm{Na}: \mathrm{Ca}$ and $\mathrm{Cl}: \mathrm{SO}_{4}$ ratios of $4: 1$ in order to get appropriate results. Fifteen-day-old seedlings were harvested to determine their shoot and 
root length as well as fresh weight (FW). Then, plants were dried in oven for $48 \mathrm{~h}$ to $72 \mathrm{~h}$ at $60{ }^{\circ} \mathrm{C}$ to obtain constant dry weight (DW).

\section{Biochemical and physiological parameters}

The shoot and root tissues were extracted in chilled pestle and mortar with Na-phosphate buffer (0.05 M, pH 7.0), EDTA (0.001 M) and PVP (1\%, Polyvinyl pyrrolidone). The homogenate was centrifuged at $15,000 \times g$ for $20 \mathrm{~min}$ at $4{ }^{\circ} \mathrm{C}$ and the supernatant was used for measuring enzyme activities.

\section{Antioxidant enzyme assays}

GlyII activity was assayed according to Antognelli et al. (2003). The assay mixture contained DTNB $(0.5 \mathrm{ml}$ of $0.2 \mathrm{mM})$, enzyme extract $(0.2 \mathrm{ml})$, Tris-HCl buffer $(1.0 \mathrm{ml}$ of 100 $\mathrm{mM}, \mathrm{pH}$ 7.4). Reaction was started by adding S-D-lactoylglutathione ( $0.4 \mathrm{ml}$ of $0.8 \mathrm{mM})$ and the absorbance was recorded at $412 \mathrm{~nm}\left(\varepsilon=26.6 \mathrm{mM}^{-1} \mathrm{~cm}^{-1}\right)$ with $30 \mathrm{sec}$ interval for $3 \mathrm{~min}$. The enzyme specific activity was expressed as $\mu$ moles $\mathrm{min}^{-1} \mathrm{mg}^{-1}$ protein. Glutathione peroxidase (GPX) was assayed according to Valentine and Paglia (1987). The reaction mixture composed of $\mathrm{K}$-phosphate buffer $(0.5 \mathrm{mM}), \mathrm{NaNO}_{3}(1 \mathrm{mM}), \mathrm{EDTA}(0.5$ $\mathrm{mM})$ and NADPH $(0.2 \mathrm{mM})$. The enzyme activity was recorded as decrease in absorbance at $340 \mathrm{~nm}\left(\varepsilon=6.5 \mathrm{mM}^{-1} \mathrm{~cm}^{-1}\right)$. Glutathione reductase (GR) activity was determined by using the protocol of Shaedle and Bassham (1977). The assay mixture composed of Tris-HCl buffer (50 mM, pH 7.5), EDTA (0.1 mM), $\mathrm{MgCl}_{2}(3 \mathrm{mM}), \mathrm{GSSG}(0.5 \mathrm{mM})$ and NADPH $(0.15 \mathrm{mM})$. The activity was recorded as decrease in absorbance at $340 \mathrm{~nm}$ $\left(\varepsilon=6.2 \mathrm{mM}^{-1} \mathrm{~cm}^{-1}\right)$. Glutathione S-transferase activity was estimated as decrease in absorbance at $340 \mathrm{~nm}\left(\varepsilon=9.8 \mathrm{mM}^{-1} \mathrm{~cm}^{-1}\right)$ with $30 \mathrm{sec}$ interval for $3 \mathrm{~min}$ (Mannervik and Guthenberg 1981). The reaction mixture composed of Na-phosphate buffer (100 mM, $\mathrm{pH}$ 6.5), CDNB (1 mM, 1-chloro-2,4-dinitrobenzene) and reduced glutathione (1 mM). Superoxide dismutase (SOD) activity was assayed by the method of Becana et al. (1986) based on inhibition of photochemical reduction of nitroblue tetrazolium (NBT). Reagents used for assay included Na-phosphate buffer (50 mM, pH 7.8), methionine (14.3 mM), riboflavin $(2.2 \mu \mathrm{M})$, NBT $(82.5 \mu \mathrm{M})$, EDTA $(0.1 \mathrm{mM})$ and $100 \mu \mathrm{L}$ enzyme extract. The reaction was run under illumination of $15 \mathrm{~W}$ fluorescence light for $10 \mathrm{~min}$. The absorbance of reaction mixture was determined at $560 \mathrm{~nm}$. The reaction mixture without supernatant was used as control and a dark control mixture act as a blank. One unit of SOD activity was defined as amount of enzyme that is able to inhibit tetrazolium blue reduction by $50 \%$ under assay condition.

\section{Antioxidant analyses}

Glutathione (GSH) content of fresh samples was measured by the procedure of Beutler et al. (1963). One ml tissue extract was mixed with glacial m-phosphoric acid (1.67 g), NaCl $(30 \mathrm{~g})$ and $\mathrm{Na}_{2}$ EDTA $(0.2 \mathrm{~g})$ in a total volume of $100 \mathrm{ml}$ and centrifuged at $1,000 \times \mathrm{g}$ for 
$10 \mathrm{~min}$. The supernatant $(1 \mathrm{ml})$ collected was added to $\mathrm{Na}_{2} \mathrm{HPO}_{3}(4 \mathrm{ml}$ of $0.3 \mathrm{M}), \mathrm{DTNB}$ $(0.5 \mathrm{ml})$ and the absorbance of yellow color was recorded at $412 \mathrm{~nm}$ within $10 \mathrm{~min}$. Ascorbic acid content was measured according to method of Luwe et al. (1993). $0.5 \mathrm{~g}$ of tissue sample was homogenized in TCA $(1 \% \mathrm{w} / \mathrm{v})$ and centrifuged at $12,000 \times \mathrm{g}$ for 20 min. The supernatant obtained was mixed with potassium phosphate buffer $(\mathrm{pH} 7.0)$ and ascorbate oxidase. The oxidation of ascorbate was then recorded at $265 \mathrm{~nm}$.

\section{Metabolite analyses}

Hydrogen peroxide $\left(\mathrm{H}_{2} \mathrm{O}_{2}\right)$ was estimated by homogenizing the tissue $(0.5 \mathrm{~g})$ in TCA $(0.1 \%)$ and centrifuged at $10,000 \times g$ for $25 \mathrm{~min}$ (Noreen and Ashraf 2009). The supernatant obtained was used for estimation of $\mathrm{H}_{2} \mathrm{O}_{2}$ content. MDA, product of lipid peroxidation was estimated by the method of Heath and Packer (1968). The sample was homogenized in TCA $(0.1 \%)$ and then added to TBA $(5 \mathrm{ml})$ solution which contained TBA $(0.5 \%)$ and TCA (20\%). The whole mixture was heated for $30 \mathrm{~min}$ at $90{ }^{\circ} \mathrm{C}$, cooled and then centrifuged at $10,000 \times g$ for $15 \mathrm{~min}$. The absorbance of color was recorded at 532 and $600 \mathrm{~nm}$. Mean of the readings in triplicate with extinction coefficient of $155 \mathrm{mM}^{-1} \mathrm{~cm}^{-1}$ was used to calculate lipid peroxides and expressed as $\mu$ mol MDA ${ }^{-1}$ FW. Sugar content of fresh samples was measured by the protocol given by Dubois et al. (1956). Sodium $\left(\mathrm{Na}^{+}\right)$and potassium $\left(\mathrm{K}^{+}\right)$analysis was done as described by Yeo and Flowers (1983). The tissue was first dried in oven at $60{ }^{\circ} \mathrm{C}$ for $48 \mathrm{~h}$ and digested with $\mathrm{HNO}_{3} / \mathrm{HClO}_{4}$ solution (2:1). The digested sample was diluted with distilled water and the content of $\mathrm{Na}^{+}$and $\mathrm{K}^{+}$ were quantified using flame photometer.

\section{Membrane stability parameter}

Electrolyte leakage was determined as described by Valentovic et al. (2006).

\section{Chlorophyll and carotenoid content}

Total chlorophyll and carotenoid content from fresh leaf tissue was determined according to the method given by Wellburn (1994). Briefly, $0.5 \mathrm{~g}$ of fresh leaf sample was taken and incubated in $5 \mathrm{ml}$ of dimethyl sulfoxide (DMSO) for $4 \mathrm{~h}$ at $65{ }^{\circ} \mathrm{C}$. The absorbance of DMSO containing pigments was recorded at $665 \mathrm{~nm}, 649 \mathrm{~nm}$ and $480 \mathrm{~nm}$.

\section{Statistical analysis}

All analyses were carried out in triplicate and values were presented as mean \pm SD of three replicates. Data for various parameters among six wheat genotypes were statistically analyzed by one-way analysis of variance (ANOVA) at the probability level of $\mathrm{p}<0.05$ using multiple comparisons (Tukey's post hoc test) by SPSS V16.0 software. The LSD values were analyzed by factorial CRD (Software CPCS1). 


\section{Results}

\section{Length and biomass}

The present study showed that shoot and root length, fresh weight and dry weight were significantly decreased with increase in the level of salinity but there was less reduction in case of Kharchia and transgenic GlyII lines. Under less salt concentration $(150 \mathrm{mM}$ $\mathrm{NaCl}$ ), the adverse effect of salinity stress was less conspicuous than at higher concentration $(250 \mathrm{mM} \mathrm{NaCl})$. With the application of $150 \mathrm{mM}$ and $250 \mathrm{mM} \mathrm{NaCl}$, shoot length was reduced by $20 \%$ and $43 \%$, root length by $22 \%$ and $54 \%$, shoot fresh weight by $28 \%$ and $49 \%$, root fresh weight by $32 \%$ and $63 \%$, shoot dry weight by $23 \%$ and $52 \%$ and root dry weight by $31 \%$ and $60 \%$, respectively, in comparison to control condition (Fig. S1*). The wheat genotype Kharchia 65 and G-1-13 line were less affected by increasing salt stress whereas PBW 621 was most affected. The maximum reduction in shoot length was observed in PBW 621 (50\%) while minimum reduction in shoot fresh and dry weight wasfound in Kharchia 65 (43\% and 45\%) and G-1-13 (44\% and 48\%) at $250 \mathrm{mM} \mathrm{NaCl}$.

\section{GlyII and other antioxidant enzymes}

Root and shoot seedlings were assayed to determine the activity of different antioxidant enzymes such as GlyII, GPX, GR, GST and SOD under control and salt treatments (150 $\mathrm{mM}$ and $250 \mathrm{mM} \mathrm{NaCl}$ ). The GlyII activity increased in all wheat genotypes, but the maximum increase was reported in GlyII transgenic lines $(77-84 \%$ at $250 \mathrm{mM} \mathrm{NaCl})$ (Fig. S2). Similarly, GPX activity was increased by $1.42-$ to 3.89 -fold in the shoot and 1.59 to 2.87 fold in root at $250 \mathrm{mM} \mathrm{NaCl}$ whereas 1.4 -fold decrease was recorded in shoot and root of PBW 621 cultivar (Fig. S2). A similar trend was observed for GR and SOD activities in shoot and root under high salinity stress. In shoot of wheat seedling, the highest SOD activity was observed in G-1-13 (2.40 fold) followed by Kharchia 65 (2.35 fold) at $250 \mathrm{mM} \mathrm{NaCl}$ as compared to control (Fig. S2). The GR activity increased 34 to $84 \%$ in shoot and 20 to $41 \%$ in root under $250 \mathrm{mM} \mathrm{NaCl}$ stress. The maximum increase in GR activity was observed in G-1-13 (84\%) followed by G-2-2 (74\%), G-3-4 (70\%) and Kharchia $65(68 \%)$ in the shoot (Fig. S2). On the other end, GST activity decreased with high salt stress in both the shoot (48-68\%) and root (14-62\%) as shown in Fig. S3. The minimum decrease in GST activity was observed in roots of G-1-13 (14\%) followed by G-2-2 (19\%) and G-2-3 (21\%).

\section{Glutathione and ascorbic acid}

High salt stress increased the glutathione content in shoot (22 to 79\%) and root (23 to $62 \%$ ) of studied wheat genotypes. Highest accumulation of glutathione was observed at $250 \mathrm{mM} \mathrm{NaCl}$ in G-1-13 (79\%) followed by G-2-2 (77\%) and lowest in PBW 621 (22\%) in shoot. Shoots showed higher increase in glutathione content than roots at $250 \mathrm{mM}$

*Further details about the Electronic Supplementary Material (ESM) can be found at the end of the article. 
$\mathrm{NaCl}$ (Fig. S3). The concentration of ascorbic acid decreased with increasing salt stress $(150 \mathrm{mM}$ and $250 \mathrm{mM} \mathrm{NaCl})$ in both shoot and root (Fig. S3) while the least decline was observed in Kharchia 65 (28.12 $\left.\mu \mathrm{mol} \mathrm{g}^{-1} \mathrm{FW}\right)$ followed by G-1-13 (27.96 $\left.\mu \mathrm{mol} \mathrm{g}^{-1} \mathrm{FW}\right)$ in shoot and the highest decline was recorded in root of PBW $621\left(16.23 \mu \mathrm{mol} \mathrm{g}^{-1} \mathrm{FW}\right)$.

\section{Hydrogen peroxide, lipid peroxide and soluble sugars}

Salt treatment caused a marked increase in the level of $\mathrm{H}_{2} \mathrm{O}_{2}$ content in both shoot and root at $250 \mathrm{mM} \mathrm{NaCl}$ while the maximum increase was recorded in root of PBW 621 (78\%) (Fig. S4). In case of shoot, the minimum increase in $\mathrm{H}_{2} \mathrm{O}_{2}$ content was observed in G-1-13 (23\%) followed by Kharchia 65 (24\%) and G-3-4 (24\%). Similarly, the effect of increasing salinity stress was measured in terms of MDA content which increased at 150 $\mathrm{mM}$ and $250 \mathrm{mM} \mathrm{NaCl}$ concentration (Fig. S4) while the minimum increase was found in G-1-13 (32\%) followed by Kharchia $65(33 \%)$ in the shoot. The soluble sugar content also increased in the shoot (51-117\%) and in root (50-91\%) at $250 \mathrm{mM} \mathrm{NaCl}$ concentration with maximum increase was observed in shoots of Kharchia $65(117 \%)$ followed by G-1-13 (103\%).

\section{Chlorophyll and carotenoid}

The chlorophyll and carotenoid contents decreased with higher $\mathrm{NaCl}$ concentration in growth medium (Fig. S5). Maintenance of chlorophyll content has been observed in salt tolerant Kharchia 65, Kharchia local and GlyII transgenic lines i.e. less decrease in chlorophyll content in these lines as compared to salt sensitive PBW 621. Carotenoid content in Kharchia 65 decreased by $6 \%, 34 \%$ at $150 \mathrm{mM}$ and $250 \mathrm{mM} \mathrm{NaCl}$, respectively, while $36 \%, 75 \%$ decrease was found in PBW 621 .

\section{$\mathrm{Na}^{+} / \mathrm{K}^{+}$analysis and electrolyte leakage}

High salt stress significantly affected the $\mathrm{Na}^{+}$and $\mathrm{K}^{+}$contents in all the studied wheat genotypes. The content of $\mathrm{Na}^{+}$increased with an increase in $\mathrm{NaCl}$ concentration from 150 $\mathrm{mM}$ (1.63 to 2.02 fold) to $250 \mathrm{mM}$ (3.33- to 4.89 -fold) (Fig. S5). The minimum increase in $\mathrm{Na}^{+}$content was obtained in Kharchia 65 as compared to other genotypes at $250 \mathrm{mM}$ $\mathrm{NaCl}$. However, $\mathrm{K}^{+}$content decreased with the application of $\mathrm{NaCl}$ in the range of 3.17to 4.25 -fold with highest decrease was found in PBW 621 (4.25-fold) at $250 \mathrm{mM} \mathrm{NaCl}$ (Fig. S5).

\section{Discussion}

The components of salt tolerance in the set of wheat lines, evaluated would manifest in morpho-physiological as well as biochemical aspects related to scavenging of free radicals, osmotic adjustment and membrane stability under high salinity. Salt stress leads to several changes in plant cell, which results in lethal effect on their structure and function. 
Salinity significantly reduced the length and biomass of wheat seedlings but the reduction was more pronounced at $250 \mathrm{mM} \mathrm{NaCl}$ concentration. However, Kharchia 65, G-1-13, G-3-2, G-2-2 and Kharchia local showed minimum growth reduction and maintained higher plant biomass as compared to PBW 621. In addition, Kharchia 65 followed by G-1-13 reported as more salt tolerant genotypes in response to high salinity which is evident due to less reduction in root/shoot length and biomass as compared to other genotypes (Fig. S1). Research findings indicate that an increase in tissue maintenance process is the primary cause of growth during stress, which could represent a mechanism of adaptation to salinity (Flower and Yeo 1995). Tolerance mechanisms are capable of maintaining the growth of shoot and reproductive parts even under stress in Kharchia 65 which is one of the salt-resistant attributes of this wheat line under salinity stress (Joshi et al. 1980). The GlyII transgenic line (G-1-13) also showed similar type of tolerance behavior as of Kharchia 65. Likewise, salt tolerance mechanism in chickpea was related to higher maintenance of leaf relative water content (Singh et al. 2018) which enhanced higher water absorption and low tissue transpiration, thus acclimatizing the crop for better partitioning of assimilates towards root system.

The glyoxalase pathway consists of two enzymes (Gly1 and GlyII) that are closely associated with tolerance to salinity. For example, transgenic rice and tobacco plants harboring rice GlyII gene, in which overexpression of GlyII enhances tolerance to high methylglyoxal and $\mathrm{NaCl}$ concentration (Wani and Gosal 2011). Even, the transgenic plants can assist growth and maintain ion balance as compared to non-transgenic plants. In our study, overexpressing osglyII gene from Oryza sativa in PBW 621 conferred resistance to high salinity in transgenic GlyII lines (G-1-13, G-2-2 and G-3-4) by significantly elevating GlyII activity as compared to other genotypes. The highest GlyII activity at 250 $\mathrm{mM} \mathrm{NaCl}$ concentration was shown in G-1-13 (Fig. S2). The toxic compound methylglyoxal builds up under stress conditions and its detoxification by GlyII enzymes might be a strategy for conferring tolerance against various abiotic stresses (Hoque et al. 2016).

The activity of antioxidant enzymes (GPX, GR, SOD) increased under stressful condition which correlates with increased stress tolerance (Gill and Tuteja 2010). GPX plays a major role in scavenging $\mathrm{H}_{2} \mathrm{O}_{2}$ generated under the high salt concentration. It catalyses the dismutation of $\mathrm{H}_{2} \mathrm{O}_{2}$ to oxidized glutathione (GSSG) and water with the use of GSH. For instance, in transgenic tomato, overexpressing GPX gene resulted in higher tolerance against various abiotic stresses (Herbette et al. 2011). During this study, GST activity decreased with increasing $\mathrm{NaCl}$ concentration but in the case of root, the decrease was less in transgenic lines and Kharchia 65. The higher levels of GR activity in root and shoot of salt stressed tolerant cultivars indicated a more active ascorbate-glutathione pathway than the sensitive cultivar. This cycle has been implicated in mitigating the effect of ROS and in maintaining a higher ratio of GSH/GSSG (Noctor et al. 2012; Ghosh et al. 2014). GSH content is regulated by two enzymes (GlyII and GR), which serve as a protective system against oxidative damage. Apparently, GSH content increased with high salinity stress and this increase could be responsible for the increase in GPX activity. The higher increase in GSH content was found in shoot of G-1-13 followed by G-2-2, G-3-4 and Kharchia 65 (Fig. S3). Sharma and Dubey (2005) have suggested that increase in 
levels of GSH would confer better antioxidative protection which might be considered as an acclimation criterion.

SOD constitutes the first line of defense against ROS, which plays an important role in protecting cells against oxidative damage (Gill and Tuteja 2010). It catalyzes the dismutation of superoxide ion to oxygen and $\mathrm{H}_{2} \mathrm{O}_{2}$ which is further detoxified by other antioxidant enzymes. In the present study, SOD activity increased with increasing level of salinity and the activity was highest in tolerant genotypes (Kharchia 65, G-1-13, G-2-2, G-3-4 and Kharchia local) as compared to PBW 621. Invariably, increased activity of SOD in roots helped the seedlings to combat salt stress by replenishing toxic superoxide radical. Kaya et al. (2013) also reported the increased SOD activity in the leaves of salt-stressed maize plants.

High salt stress increased $\mathrm{H}_{2} \mathrm{O}_{2}$ concentration in different compartments of plant cell through enzymatic or nonenzymatic processes (Foyer et al. 1997). In our study, salinity treatment $(250 \mathrm{mM} \mathrm{NaCl})$ caused a marked increase in $\mathrm{H}_{2} \mathrm{O}_{2}$ content in PBW 621 genotype as compared to Kharchia and transgenic lines. Furthermore, $\mathrm{H}_{2} \mathrm{O}_{2}$ accumulation under high salinity condition may be a signal to initiate an adaptive response to stress. The increase in ROS production is closely related to disruption of membrane stability and thereby increased electrolyte leakage (Kumar et al. 2015, 2017). Hence, lipid peroxidation in terms of MDA content and electrolyte leakage was used as a criteria to establish membrane integrity during stress conditions in different cultivars. In our study, with the application of $\mathrm{NaCl}$, the maximum increase in MDA content was recorded in PBW 621 and the minimum in G-1-13 and Kharchia 65. PBW 621 also showed increased electrolyte leakage when compared with other cultivars. Together, results suggest that the increase in the content of $\mathrm{H}_{2} \mathrm{O}_{2}$, MDA and increased electrolyte leakage caused peroxidation of the lipid membrane, thus disrupting the cell permeability.

$\mathrm{Na}^{+}$accumulation adversely affect chlorophyll synthesis by increasing the activity of chlorophyll degrading enzyme, chlorophyllase, which can be treated as a marker of oxidative stress (Noreen and Ashraf 2009). In the present study, increase in concentration of $\mathrm{NaCl}$ reduced chlorophyll content in all wheat genotypes but the tolerant genotypes (Kharchia 65 and G-1-13) maintained its higher content as also reported earlier (Gurmani et al. 2014) in wheat. Due to maximum reduction of chlorophyll content in PBW 621, this genotype can be regarded as most salt sensitive one (Fig. S5). Salinity stress also caused decrease in carotenoid content in all genotypes but Kharchia 65 and G-1-13 maintained its higher content. Sugar content increased with increasing salinity level with maximum level achieved in salt tolerant ones i.e. Kharchia 65 and G-1-13 (Fig. S4). The increase in sugar level was in agreement with earlier findings of Kumar et al. (2017) in wheat. Infact, sugars might contribute to salt stress tolerance either by serving as osmoticum or as respiratory substrates.

Our results depicted that with an increase in $\mathrm{NaCl}$ concentration, the levels of $\mathrm{Na}^{+}$ content increased differentially in wheat genotypes due to their different genetic compositions (Fig. S5). The low uptake of $\mathrm{Na}^{+}$by roots and high selectivity for $\mathrm{K}^{+}$can be considered as physiological mechanisms for salt tolerance (Flowers 2004). The minimum $\mathrm{Na}^{+}$ion concentration was recorded in leaves of Kharchia 65 followed by G-1-13 as in 
Fig. S5. Salt tolerant genotypes infact possess exclusion mechanism that control the entry of $\mathrm{Na}^{+}$into root and efflux the excessive $\mathrm{Na}^{+}$from photosynthetic tissues (Moller et al. 2009). Conversely, $\mathrm{K}^{+}$content decreased with increasing level of salinity but the highest level of $\mathrm{K}^{+}$content was found in Kharchia 65 and G-1-13.

Our findings demonstrate that the salt-tolerant genotypes retain selectivity for $\mathrm{K}^{+}$over $\mathrm{Na}^{+}$and maintains lower $\mathrm{Na}^{+} / \mathrm{K}^{+}$ratio under high salinity but the salt sensitive genotypes failed to do so. According to the elevated GSH content and higher stress resistance of the transgenic lines, GlyII activity may both participate in the detoxification process of methylglyoxal and in the regeneration of GSH pool and thus may play a role in the maintenance of redox homeostasis. The two types of salt tolerance mechanisms comprising MG pathway and antioxidant defense system have a convergent influence on osmotic adjustments and expression of antioxidants. The same convergence is evident for expression of tolerance at morpho-physiological level. There seem to be good prospects for combining the salt mechanisms in a single genotype.

\section{References}

Antognelli, C., Romani, R., Baldracchini, F., De Santis, A., Andreani, G., Tasela, V. 2003. Different activity of glyoxalase system in specimens of Sparus auratus exposed to sublethal copper concentrations. Chem. Biol. Interact. 142:297-305.

Ashraf, M. 2004. Some important physiological selection criteria for salt tolerance in plants. Flora 199:361376.

Becana, M., Aparicio-Tejo, P., Irigoyan, J.J., Sanchez-Diaz, M. 1986. Some enzymes of hydrogen peroxide metabolism in leaves and root nodules of Medicago sativa. Plant Physiol. 82:1169-1171.

Beutler, E., Durron, O., Kally, B.M. 1963. Improved method for determination of blood glutathione. J. Lab. Clin. Med. 61:882-888.

Das, K., Roychoudhury, A. 2014. Reactive oxygen species (ROS) and response of antioxidants as ROSscavengers during environmental stress in plants. Front. Environ. Sci. 2:53.

Dubois, M., Gilles, K.A., Hamilton, J.K., Rebers, P.A., Smith, F. 1956. Colorometric method for determination of sugars and related substances. Anal. Chem. 28:350-356.

FAO. 2016. FAO Soils Portal. Available at: http://www.fao.org/soils-portal/soilmanagement/management-ofsome-problem-soils/salt-affected soils/more information-on-salt-affected-soils/en.

Flowers, T.J. 2004. Improving crop salt tolerance. J. Exp. Bot. 55:307-319.

Foyer, C.H., Lopez-Delgado, H., Dat, J.F., Scott, I.M. 1997. Hydrogen peroxide and glutathione-associated mechanism of acclimatory stress tolerance and signaling. Plant Physiol. 100:241-254.

Ghosh, A., Pareek, A., Sopory, S.K., Singla-Pareek, S.L. 2014. A glutathione responsive rice glyoxalase II, OsGLYII-2, function in salinity adaptation by maintaining better photosynthesis efficiency and anti-oxidant pool. Plant J. 80:93-105.

Gill, S.S., Tuteja, N. 2010. Reactive oxygen species and antioxidant machinery in abiotic stress tolerance in crop plants. Plant Physiol. Biochem. 48:909-913.

Gorham, J., Hardy, C., Wyn Jones, R.G., Joppa, LR., Law, C.N. 1987 Chromosomal location of K/Na discrimination character in the D genome of wheat. Theor. Appl. Genet. 74:584-588.

Gupta, B.K., Sahoo, K.K., Ghosh, A., Tripathi, A.K., Khalid, A., Das, P., Singh, A.K., Pareek, A., Sopory, S.K., Singla-Pareek, S.L. 2018. Manipulation of glyoxalase pathway confers tolerance to multiple stresses in rice Plant Cell and Environ. 41:1186-1200.

Gurmani, A.R., Khan, S.U., Mabood, F., Ahmed, Z., Butt, S.J., Din, J., Mujeeb-Kazi, A., Smith, D. 2014. Screening and selection of synthetic hexaploid wheat germplasm for salinity tolerance based on physiological and biochemical characters. Int. J. Agric. Biol. 16:681-690. 
Heath, R.L., Packer, L. 1968. Photoperoxidation in isolated chloroplasts - Kinetics and stoichiometery of fatty acid peroxidation. Arch. Biochem. Biophys. 125:189-198.

Herbette, S., Labrouhe, D.T., Drevet, J.R., Roeckel-Drevet, P. 2011. Transgenic tomatoes showing higher glutathione peroxidase antioxidant activity are more resistant to an abiotic but more susceptible to biotic stress. Plant Sci. 180:548-553.

Hoagland, D.R., Arnon, D. 1950. The water culture method for growing plants without soil. Circular 347, California Agricultural Experiment Station, University of California-Berkeley, Berkeley Ca, USA.

Hoque, M.A., Uraji, M., Banu, M.N.A., Mori, I.C., Nakamura, Y., Murata, Y. 2012. The effect of methylglyoxal on glutathione S-trans-ferase from Nicotiana tabacum. Biosci. Biotechnol. Biochem. 74:2124-2126.

Hoque, T.S., Hossain, M.A., Mostofa, M.G., Burritt, D.J., Fujita, M., Tran Lam-Son, P. 2016. Methylglyoxal: An emerging signaling molecule in plant abiotic stress responses and tolerance. Front. Plant Sci. 7:1341.

Hussain, M.I., Shah, S., Hussain, S., Iqbal, K. 2002. Growth, yield and quality response of three wheat (Triticum aestivum L.) varieties to different levels of N, P and K. Int. J. Agric. Biol. 4(3):362-364.

Joshi, Y.C., Ali, Q., Bal, A.R., Rana, R.S. 1980. Sodium/potassium index of wheat seedlings in relation to sodicity tolerance, International symposium on salt affected soils, Feb 18-21. CSSRI. Karnal pp. 451-460.

Kapoor, D. 2015. Redox homeostasis in plants under abiotic stress: role of electron carriers, energy metabolism mediators and proteinaceous thiols. Front. Environ. Sci. 3:13.

Kaur, R. 2014. Genetic transformation of bread wheat (Triticum aestivum L.) by 'particle gun and Agrobacterium-mediated approaches. Ph.D. dissertatioin. Punjab Agricultural University, Ludhiana, India.

Kaya, C., Ashraf, M., Dikilitas, M., Tuna, A.L. 2013. Alleviation of salt stress induced adverse effects on maize plants by exogenous application of indoleacetic acid (IAA) and inorganic nutrients - a field trial. Aust. J. Crop Sci. 7:249-254.

Kumar, M., Hasan, M., Arora, A., Gaikwad, K., Kumar, S., Rai, R.D. 2015. Sodium chloride-induced spatial and temporal manifestation in membrane stability index and protein profiles of contrasting wheat (Triticum aestivum L.) genotypes under salt stress. Ind. J. Plant Physiol. 20:271-275.

Kumar, S., Beena, A.S., Awana, M., Singh, A. 2017. Physiological, biochemical, epigenetic and molecular analyses of wheat (Triticum aestivum) genotypes with contrasting salt tolerance. Front. Plant Sci. 8:1151.

Luwe, M.W.F., Takahama, U., Heber, U. 1993. Role of ascorbate in detoxifying ozone in the apoplast of spinach (Spinacia oleracea L.) leaves. Plant Physiol. 101:969-976.

Mannervik, B., Guthenberg, C. 1981. Glutathione transferase (human placenta). Methods Enzymol. 77:231235.

Miller, G., Suzuki, N., Ciftci-Yilmaz, S., Mittler, R. 2010. Reactive oxygen species homeostasis and signalling during drought and salinity stresses. Plant Cell Environ. 33:453-467.

Moller, I.S., Gilliham, M., Jha, D., Mayo, G.M., Roy, S.J., Coates, J.C. 2009. Shoot Na ${ }^{+}$exclusion and increased salinity tolerance engineered by cell type-specific alteration of $\mathrm{Na}^{+}$transport in Arabidopsis. Plant Cell 21:2163-2178.

Munns, R., James, R.A., Islam, S., Colmer, T.D. 2011. Hordeum marinum-wheat amphiploids maintain higher leaf K:Na and suffer less leaf injury than wheat parents in saline conditions. Plant Soil 348:365-377.

Noctor, G., Mhamdi, A., Chaouch, S., Han, Y.I., Neukermans, J., Marquez-Garcia, B. 2012. Glutathione in plants: an integrated overview. Plant Cell Environ. 35:454-484.

Noreen, Z., Ashraf, M. 2009. Changes in antioxidant enzymes and some key metabolites in some genetically diverse cultivars of radish (Raphanus sativus L.). Environ. Exp. Bot. 67(2):395-402.

Oyiga, B.C., Sharma, R.C., Shen, R.C., Baum, M., Ogbonnaya, F.C., Leon, J., Ballvora, A. 2016. Identification and characterization of salt tolerance of wheat germplasm using multivariable screening approach. J. Agron. Crop Sci. 202(6):472-485.

Passaia, G., Spagnolo, F.L., Caverzan, A., Jardim-Messeder, D., Christoff, A.P., Gaeta, M.L., de Araujo Mariath, J.E., Margis, R., Margis-Pinheiro, M. 2013. The mitochondrial glutathione peroxidase GPX3 is essential for $\mathrm{H}_{2} \mathrm{O}_{2}$ homeostasis and root and shoot development in rice. Plant Sci. 208:93-101.

Rahaie, M., Xue, G.P., Schenk, P.M. 2013. The role of transcription factors in wheat under different abiotic stresses. In: Vahdati, K. and Leslie, C. (eds) Abiotic Stress. Plant Responses and Applications in Agriculture. In Tech, Rijeka, Croatia, pp. 367-385. 
Sairam, R.K., Rao, K.V., Srivastava, G.C. 2002. Differential response of wheat genotypes to long-term salinity stress in relation to oxidative stress, antioxidant activity and osmolytes concentration. Plant Sci. 163:10371046.

Shaedle, M., Bassham, J.A. 1977. Chloroplast glutathione reductase. Plant Physiol. 59:1011-1012.

Sharma, P., Dubey, R.S. 2005. Drought induces oxidative stress and enhances the activities of antioxidant enzymes in growing rice seedlings. Plant Growth Regul. 46:209-221.

Singh, V., Singh, A.P., Bhadoria, J., Giri, J., Singh, J., Vineeth, T.V., Sharma, P.C. 2018. Differential expression of salt-responsive genes to salinity stress in salt tolerant and salt-sensitive rice (Oryza sativa L.) at seedling stage. Protoplasma 255:1665-1681.

Singh, J., Singh, V., Sharma, P.C. 2018. Elucidating the role of osmotic, ionic and major salt responsive transcript components towards salinity tolerance in contrasting chickpea (Cicer arietinum) genotypes. Physiol. Mol. Bio. Plants 24(3):441-453.

Singla-Pareek, S.L., Yadav, S.K., Pareek, A., Reddy, M.K., Sopory, S.K. 2008. Enhancing salt tolerance in a crop plant by overexpression of glyoxalase II. Transgenic Res. 17:171-180.

Valentine, W.N., Paglia, D.E. 1987. Studies on the quantitative and qualities characterization of glutathione peroxidase. J. Laboratory Clin. Med. 70:158-165.

Valentovic, P., Luxova, M., Kolarovic, L., Gasparikova, O. 2006. Effect of osmotic stress on compatible solutes content, membrane stability and water relations in two maize cultivars.Plant Soil Environ. 52(4):186-191.

Wani, S.H., Gosal, S.S. 2011. Introduction of OsglyII gene into Oryza sativa for increasing salinity tolerance. Biol. Plant. 55:536-540.

Wellburn, A.R. 1994. The spectral determination of chlorophylls a and b as well as total carotenoids, using various solvents with spectrophotometers of different resolution. J. Plant Physiol. 144:307-313.

Xie, J., Dai, Y., Mu, H., De, Y., Chen, H., Wu, Z., Ren, W. 2016. Physiological and biochemical responses to $\mathrm{NACl}$ salinity stress in three Roegneria (Poaceae) species. Pakistan J. Bot. 48(6):2215-2222.

Yeo, A.R., Flowers, T.J. 1983. Varietal differences in the toxicity of sodium ions in rice leaves. Physiol. Plant. 59:189-195.

\section{Electronic Supplementary Material (ESM)}

Electronic Supplementary Material (ESM) associated with this article can be found at the website of CRC at http://www.akademiai.com/content/120427/

Electronic Supplementary Figure S1. Effects of salt stress on: (A) Shoot length, (B) Root length, (C) Shoot fresh weight, (D) Root fresh weight (E) Shoot dry weight, (F) Root dry weight. Values are mean \pm SE of triplicates. Bars with different letters in a genotype represent significantly different values $(p<0.05)$. LSD values were analyzed by factorial CRD (Software CPCS1). A - Genotype, B - Treatment, AxB - genotype and treatment interaction

Electronic Supplementary Figure S2. Effects of salt stress on enzyme activities: (A) GlyII in shoot, (B) GlyII in root, (C) GPX in shoot, (D) GPX in root, (E) GR in shoot, (F) GR in root, (G) SOD in shoot and (H) in root. Values are mean $\pm \mathrm{SE}$ of triplicates. Bars with different letters in a genotype represent significantly different values $(\mathrm{p}<0.05)$. LSD values were analyzed by factorial CRD (Software CPCS1). A - Genotype, B Treatment, $\mathrm{AxB}$ - genotype and treatment interaction

Electronic Supplementary Figure S3. Effects of salt stress on: (A) GST activity in shoot, (B) GST activity in root, (C) Glutathione content in shoot, (D) Glutathione content in root, (E) Ascorbic acid content in shoot, (F) Ascorbic content in root. Values are mean \pm SE of triplicates. Bars with different letters in a genotype represent significantly different values $(\mathrm{p}<0.05)$. LSD values were analyzed by factorial CRD (Software CPCS1). A Genotype, B - Treatment, AxB - genotype and treatment interaction 
Electronic Supplementary Figure S4. Effects of salt stress on: (A) MDA content in shoot, (B) MDA content in root, (C) $\mathrm{H}_{2} \mathrm{O}_{2}$ content in shoot, (D) $\mathrm{H}_{2} \mathrm{O}_{2}$ content in root, (E) Total soluble sugars in shoot, (F) Total soluble sugars in root. Values are mean $\pm \mathrm{SE}$ of triplicates. Bars with different letters in a genotype represent significantly different values $(\mathrm{p}<0.05)$. LSD values were analyzed by factorial CRD (Software CPCS1). A Genotype, B - Treatment, AxB - genotype and treatment interaction

Electronic Supplementary Figure S5. Effects of salt stress on: (A) Chlorophyll content in leaves, (B) Carotenoid content in leaves, (C) Sodium $\left(\mathrm{Na}^{+}\right)$content in leaves, (D) Potassium $\left(\mathrm{K}^{+}\right)$content in leaves, (E) Electrolyte leakage content in leaves. Values are mean \pm SE of triplicates. Bars with different letters in a genotype represent significantly different values $(\mathrm{p}<0.05)$. LSD values were analyzed by factorial CRD (Software CPCS1). A Genotype, B - Treatment, AxB - genotype and treatment interaction 